Thorax (1967), 22, 533.

\title{
Asthma due to aluminium soldering flux
}

\author{
G. M. STER L I N G \\ From the Respiratory Department, St. George's Hospital, London, S.W.I
}

\begin{abstract}
Two patients have been studied who complained of dyspnoea after the inhalation of fumes from a new soldering flux recently developed for use in jointing aluminium which has been replacing copper as a material for electric cables. A previous survey of respiratory complaints after the use of this particular flux had failed to show any objective change in lung function, and the present cases are the first to be reported. Both subjects have been investigated by means of serial spirometry, peak flow rates, and body plethysmography following inhalation of small amounts of flux fumes; delayed and prolonged bronchoconstriction has been demonstrated. Similar results have been obtained after the inhalation of one of the main constituents of the flux, namely amino-ethyl ethanolamine, which is presumably the active allergic agent. The bronchial response is unusual in being delayed in onset but otherwise resembles pollen-sensitivity asthma rather than the infiltrative process seen in farmer's lung. The type of immune mechanism involved is speculative, but it is possible that some alteration of the aminc-ethyl ethanolamine is needed before it can react with reaginic antibody fixed in the bronchial tissues.
\end{abstract}

Bronchial hypersensitivity to inhaled allergens has been known for a long time to be the cause of asthma in typical pollen-sensitive subjects and is thought to represent an anaphylactic type of reaction between antigen and fixed reaginic antibody which produces almost immediate bronchoconstriction. In the last few years a different, nonobstructive pattern of bronchopulmonary hypersensitivity has been described, in which pulmonary infiltrations occur in association with fever and malaise. The best-known example is the condition of farmer's lung, probably caused by the inhalation of the spores of Thermopolyspora polyspora and other thermophilic fungi (Pepys and Jenkins, 1965). Two subjects have recently been seen with an unusual delayed asthmatic response to fumes of a particular soldering flux: it has been possible to reproduce typical attacks in the laboratory and to identify the causative simple organic compound.

\section{CASE HISTORIES}

CASE 1 Mr. J. B., aged 29, previously well with no history of asthma or other allergy, had worked as a cable jointer's mate for about three years. At the end of 1965 he was promoted to cable jointer and his exposure to flux fumes was increased to about 20 minutes every day. In January 1966 he first developed wheezing dyspnoea, with a productive cough, and was thought to have infective bronchitis with asthma. However, after returning to work his symptoms recurred and this cycle was repeated several times before his admission for investigation in July 1966. It was notable that the dyspnoea did not develop until some hours after the exposure to flux fumes, that it was precipitated by inereasingly short exposure, and that it lasted for several days.

At the time of investigation he was free from symptoms, and on examination no abnormality was found in the respiratory or cardiovascular systems. A chest radiograph, haemoglobin, and white blood count were normal, and respiratory function tests showed no serious airway obstruction, though his F.E.V.1.0/V.C. ratio was rather low at $62 \%$.

CASE 2 Mr. E. C., aged 42, also previously well, had been exposed to flux fumes on only two or three occasions before he developed wheezing dyspnoea, again starting a few hours after exposure and lasting several days. He gave a past history of hay-fever and of one previous attack of asthma, possibly associated with the use of another soldering flux, but there was no history of seasonal asthma or other allergy. He was symptom-free at the time of examination, when he was found to be obese but to have no abnormality of the respiratory or cardiovascular systems. His chest radiograph, haemoglobin, and white count were normal, and there was no evidence of airway obstruction on spirometry.

\section{MATERIAL AND METHODS}

ALUMINIUM SOLDERING FLUX Aluminium is being used increasingly as a material for electric cables on account of its lightness and cheapness, but it has the disadvantage of forming a tenaceous film 
of oxide when heated in the process of soldering, which is the usual way in which underground cables are jointed. Fluxes used in copper jointing have proved unsuitable for use with aluminium, and new ones have been developed. The particular one investigated consists of a mixture of aminoethyl ethanolamine, zinc oxide, and fluoroborate. The exact nature of the chemical reactions that occur when the flux is heated during soldering is not known, but the fumes contain ammonia, amine vapour, and fluoride and are alkaline in reaction, which makes it unlikely that hydrofluoric acid is present in the free state. It has been shown that the bulk of the fluoride in the fumes is particulate, not gaseous, as it is filterable, and that the main component of the fumes is a mist of unchanged amine (McCann, 1964). In view of this, attention has been directed to amino-ethyl ethanolamine as the most likely constituent of the flux to be the cause of asthma, and the effect of pure amine fumes, as well as of whole flux fumes, has been studied.

Investigations In view of their suggestive histories, the subjects were admitted to hospital for further investigation of their response to the inhalation of flux fumes. An attempt to reproduce working conditions was made by dropping a small quantity of the flux or of pure amino-ethyl ethanolamine on to a heated sheet of aluminium. The subjects then took one to three breaths of the resulting fumes, which they thought were representative of the dose taken during the jointing of a single cable. Similar inhalations were also taken by one normal subject, who acted as a control.

Changes in pulmonary function were followed at frequent intervals by three different methods :

(1) Peak expiratory flow rate (P.E.F.R.) was measured with a Wright peak flowmeter.

(2) Forced expiratory volume in 1 second, vital capacity, and inspiratory capacity (F.E.V.1.0, V.C., I.C.) were measured with a conventional lightweight spirometer.

(3) Airway resistance and functional residual capacity (F.R.C.) were measured with a body plethysmograph.

The latter was a constant volume machine of 440 litres capacity similar to that described by DuBois, Botelho, Bedell, Marshall, and Comroe (1956) and DuBois, Botelho, and Comroe (1956). After warming up for two or three minutes, the subjects performed shallow panting at about two breaths per second through a Fleisch pneumotachograph and then continued to make shallow movements against a closed shutter incorporated into the mouthpiece and remotely controlled. Theo F.R.C. was measured by closing the shutter at the end of a normal slow expiration and then instruct- $\overline{\frac{\bar{c}}{5}}$. ing the subject to start making shallow panting $\stackrel{\varnothing}{\varnothing}$ movements. The vector loops produced by these manœuvres were displayed on an oscilloscopes screen and their slopes were obtained from align- $\vec{\circ}$ ment with parallel lines ruled on a Perspex disc $\overrightarrow{\vec{H}}$ which rotated within a fixed protractor scale in front of the screen.

Six successive measurements of airway resistance and panting lung volume (hereafter referred? to as thoracic gas volume or TGV) were made, $i$ and the mean of the last five was used in calculation. After subtraction of $0.45 \mathrm{~cm} . \mathrm{H}_{2} \mathrm{O} / 1$. $/ \mathrm{sec}$.응 for the resistance of the flowmeter and mouth- piece, airway resistance was converted to its $\vec{Z}$ reciprocal, airway conductance (CA), and divided by the lung volume to give the expression $\mathrm{CA} / \frac{\Phi}{3}$ TGV. In this way a correction was made for the normal effect of lung volume on airway resistance (Nadel and Comroe, 1961). With a little training $\vec{\odot}$ both subjects were able to produce clear and. reproducible slopes, and changes in resistance and lung volume were easy to follow.

The use of the body plethysmograph enabled absolute changes in airway resistance to be followed and to be compared with changes in $\frac{\Omega}{\varrho}$ P.E.F.R. and F.E.V., which are less precise but $\stackrel{\varrho}{\Rightarrow}$ more convenient ways of assessing bronchial $\frac{0}{3}$ obstruction. It was also possible to follow changes in lung volume during asthma (Woolcock and Read, 1965, 1966), and it is hoped to report these results separately.

In addition to the inhalation tests, skin, scratch, and prick tests were performed with dilutions of $\underset{*}{*}$ flux and amino-ethyl ethanolamine.

\section{RESULTS}

Peak flow, F.E.V. $\cdot_{\cdot 1 \cdot 0}$, and CA/TGV were all measured at frequent intervals to start with and the results were compared. It was found (Fig. N 1) that they agreed well, and, in particular, or P.E.F.R. was vindicated as a means of following $N$ changes in airway resistance. In view of the simplicity of the method it was the one used most frequently, though the others were also used when 0 specifically wanted.

Case 1 was tested by the inhalation of flux $\stackrel{\oplus}{\oplus}$ fumes on three occasions and showed a consistent 0 response of delayed bronchoconstriction, which started two to three hours after exposure to the fumes and lasted for several days. Typical acute $\mathbb{\Phi}$ and long-term responses are illustrated in Figs $2 \frac{2}{\sigma}$ 


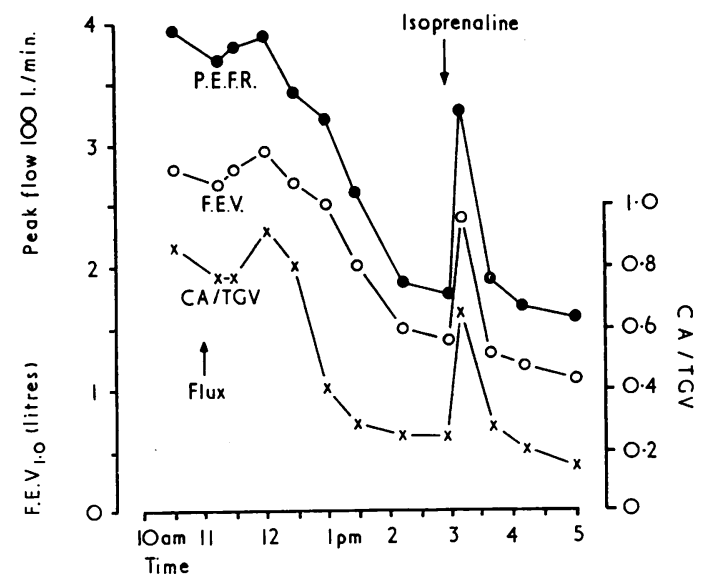

FIG. 1. Case 1. Comparative changes in CA/TGV, F.E.V..$_{1 \cdot 0}$, and P.E.F.R. after inhalation of flux fumes.

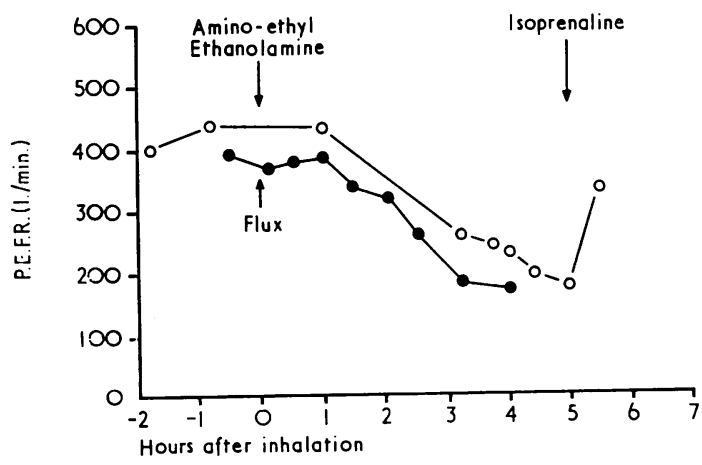

FIG. 2. Case 1. Changes in P.E.F.R. after inhalation of whole flux fumes (closed circles) and amino-ethyl ethanolamine fumes (open circles).

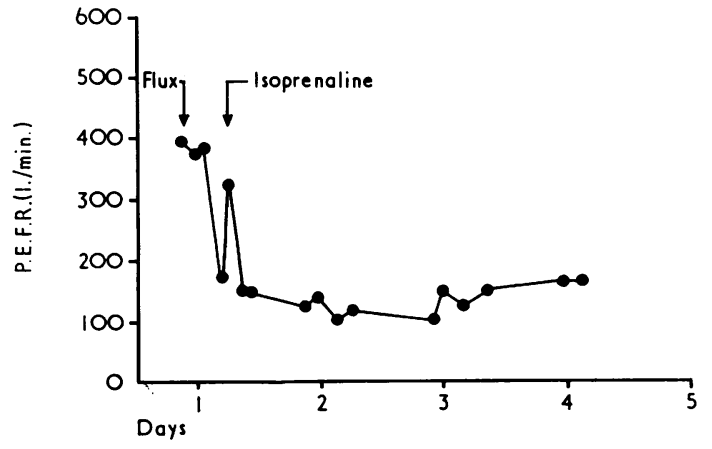

FIG. 3. Case 1. Changes in P.E.F.R. over four days after inhalation of flux fumes. and 3, where changes in peak flow have been followed after the inhalation of flux fumes. Symptomatically he developed severe asthma with a troublesome cough but little sputum. On a fourth occasion he was tested with fumes of pure amino-ethyl ethanolamine and again showed a delayed asthmatic response with a similar time course to that seen after the inhalation of whole flux fumes. Examination revealed widespread wheezing but no crepitations, and he did not develop a fever or malaise. His chest radiograph remained normal throughout, and his white blood count showed a slight eosinophilia, which reached a maximum of $6 \%$ of $7,700\left(462 / \mathrm{mm}^{3}\right)$.

Skin testing with standard allergens was negative, and scratch and prick tests with dilutions of flux and amino-ethyl ethanolamine caused no immediate, intermediate, or delayed reactions.

Case 2 was studied on two occasions, first with whole flux fumes and secondly with pure aminoethyl ethanolamine fumes. Before inhalation his resting lung function tests were normal and repeatable, and after inhalation he showed a response very similar to that of Case 1 with a latent period of about three hours followed by a severe bronchoconstriction lasting șeveral days. This was temporarily reversible with isoprenaline aerosol, and to a lesser extent with atropine, and again the effect of pure amino-ethyl ethanolamine mimicked that of whole flux (Figs 4 and 5).

Scratch and prick tests with flux and amine give no immediate or delayed responses, and the chest radiograph showed no change. Carbon monoxide uptake was measured by the 'steady-state' method at the height of the asthma and was normal. A moderate blood eosinophilia developed (Table) and $80 \%$ of the leucocytes in the sputum were eosinophils.

\section{T A B L E}

\begin{tabular}{|c|c|c|c|c|}
\hline & \multirow{2}{*}{$\begin{array}{c}\text { Total } \\
\text { W.B.C../ } \\
\text { mm. }\end{array}$} & \multicolumn{2}{|c|}{ Eosinophils } & \multirow{2}{*}{$\begin{array}{c}\text { E.S.R. } \\
\text { (Win- } \\
\text { trobe) } \\
\text { (mm./hr) }\end{array}$} \\
\hline & & $\%$ & per $\mathrm{mm} .^{3}$ & \\
\hline \multirow{2}{*}{$\begin{array}{l}\text { Before inhalation } \\
\text { Days after amine } \\
\text { fumes: } \\
\end{array}$} & 8,300 & 4 & 332 & 6 \\
\hline & $\begin{array}{l}8,400 \\
7,800 \\
5,900\end{array}$ & $\begin{array}{r}8 \\
14 \\
16\end{array}$ & $\begin{array}{r}672 \\
1,092 \\
944\end{array}$ & $\begin{array}{l}2 \\
5 \\
4\end{array}$ \\
\hline
\end{tabular}

Inhalation of these fumes by one normal subject caused minimal immediate bronchoconstriction, detectable only with the body plethysmograph, and no delayed response. Skin tests with dilute solutions of flux and amino-ethyl ethanolamine were all negative. 


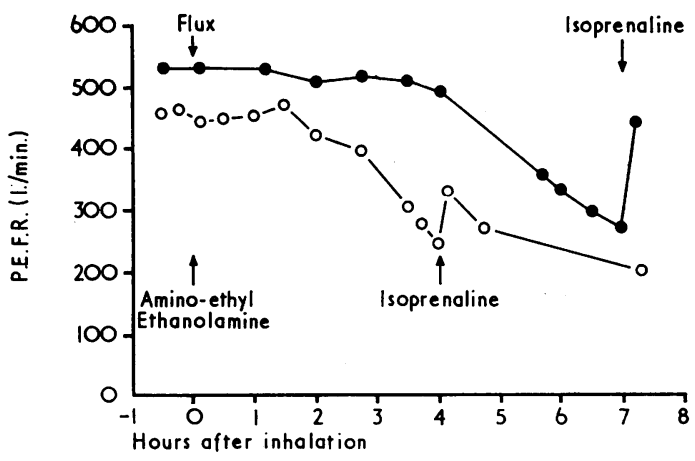

FIG. 4. Case 2. Changes in P.E.F.R. after inhalation of white flux fumes (closed circles) and amino-ethyl ethanolamine fumes (open circles).

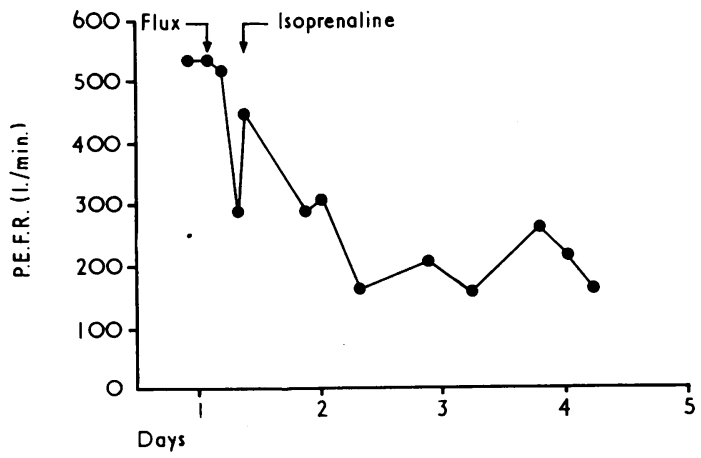

FIG. 5. Case 2. Changes in P.E.F.R. over four days after inhalation of flux fumes.

\section{DISCUSSION}

Both the subjects investigated here regularly developed severe asthma some hours after the inhalation of fumes of whole soldering flux or pure amino-ethyl ethanolamine. Since aluminium is becoming increasingly popular as a cable material, this represents a potential industrial hazard, but a previous large-scale study by McCann (1964) suggested that the problem was unlikely to be numerically serious. She investigated about 3,000 cable jointers and their mates at a time when aluminium was used in roughly one-third of jointing operations and found only one dubious case of bronchial sensitivity to soldering flux fumes. By now, many more men must be at risk, but the present two cases are the first ones to be described.
The mechanism of the asthma is presumably allergic rather than toxic, since it is so rare and can be provoked by very small doses of fume. The reaction resembles pollen-sensitivity asthma in consisting of bronchoconstriction and eosino- ® philia without radiographic changes or impair- $\vec{A}$ ment of gas transfer, but it is unusual in its late onset, several hours after the inhalation of the $\vec{\omega}$ provoking material. Usually allergic asthma is thought to be an anaphylactic type of reaction due $\vec{x}$ to a combination of the challenging antigen with fixed reaginic antibodies in the bronchial tissues of (Coombs and Gell, 1963) and comes on within a is few minutes. However, a biphasic response may $\stackrel{\omega}{\omega}$ occur, consisting of mild immediate broncho- 은 constriction, which becomes more severe after a few hours, and it is just possible that mild pure $Z$ delayed asthma may have been missed in the past if patients have not been followed for several hours after a test inhalation.

Typical delayed pulmonary hypersensitivity of $\vec{\oplus}$ the type seen in farmer's lung or bird-breeder's lung (Hargreave, Pepys, Longbottom, and Wraith, 1966) differs from allergic asthma in presenting with fever, malaise, and pulmonary infiltrations, but not bronchoconstriction, and is usually associated with precipitating antibodies and a positive Arthus-type skin reaction.

Thus the response described in the present $\overrightarrow{\vec{O}}$ cases was most like pollen asthma, but unusual 3 features were the delay in onset and the absence of any immediate skin reactions, though the latter do not always correlate well with bronchial reactivity even in established pollen sensitivity. The cause for the delay is quite speculative, but $\stackrel{2}{x}$ possibly some alteration of the amino-ethyl ethanolamine is necessary before it acts as an antigen and can combine with antibody fixed on the bronchial cells. In fact, in Case 2 a very slight, brief, immediate bronchoconstriction could 은 be detected by the body plethysmograph (a more $\rightarrow$ sensitive instrument than the peak flowmeter), but it is probable that this was a non-specific reaction $N$ to an inhaled irritant since it resembled that seen after the inhalation of carbon particles (Widdi- $N$ combe, Kent, and Nadel, 1962) or cigarette smoke w (Nadel and Comroe, 1961), and also occurred in one normal control who developed no delayed 0 reaction.

Whatever the mechanism of flux asthma, the active agent seems to be the organic constituent, amino-ethyl ethanolamine, inhalation of which provoked attacks very similar to those which followed whole-flux fumes. The bronchoconstric- $\mathbb{D}$ tion could be largely reversed by the inhalation of $\bar{\sigma}$ 
isoprenaline in the early stages of an attack, but atropine was considerably less effective: this suggests that the constriction is mainly due to direct action rather than to a vagal reflex initiated by irritation of tracheobronchial receptors.

I wish to thank Dr. J. C. Batten for his interest and encouragement, Dr. J. Pepys, of the Brompton Hospital, who referred the second subject for investigation and advised on allergic responses, and Miss F. A. Boother for her help in carrying out many of the tests. This study was supported by a research grant from the Board of Governors, St. George's Hospital, London, S.W.1.

\section{REFERENCES}

Coombs, R. R. A., and Gell, P. G. H. (1963). In Clinical Aspects of Immunology, ed. P. G. H. Gell and R. R. A. Coombs, p. 317. Blackwell, Oxford.
DuBois, A. B., Botelho, S. Y., Bedell, G. N.. Marshall, R., and Comroe, J. H., Jr. (1956). A rapid plethysmographic method for measuring thoracic gas volume. J. clin. Invest., 35, 322.

_- and Comroe, J. H., Jr. (1956). A new method for measuring airway resistance in man using a body plethysmograph. Ibid., 35, 327.

Hargreave, F. E., Pepys, J., Longbottom, J. L., and Wraith, D. G. (1966). Bird breeder's (fancier's) lung. Lancet, 1, 445.

McCann, Joan K. (1964). Health hazard from flux used in joining aluminium electricity cables. Ann. occup. Hyg., 7, 261.

Nadel, J. A., and Comroe, J. H., Jr. (1961). Acute effects of inhalation of cigarette smoke on airway conductance. J. appl. Physiol., 16, 713.

Pepys, J., and Jenkins, P. A. (1965). Precipitin (F.L.H.) test in farmer's lung. Thorax, 20, $2 \mathrm{i}$.

Widdicombe, J. G., Kent, D. C., and Nadel, J. A. (1962). Mechanism of bronchoconstriction during inhalation of dust. J. appl. Physiol., 17, 613.

Woolcock, Ann J., and Read, J. (1965). Improvement in bronchial asthma not reflected in forced expiratory volume. Lancet, 2,1323 . Med., 41, 259. 